\title{
Enxerto ósseo autógeno de crista ilíaca para tratamento de defeito mandibular
}

Autogenous bone graft from the iliac crest for the treatment of mandibular defects

Injerto óseo autógeno de la cresta ilíaca para el tratamiento de defectos mandibulares

Maylson Alves Nogueira BARROS 1

Vitor Bruno TESLENCO1

Guilherme Nucci REIS ${ }^{2}$

Everton Floriano PANCINI ${ }^{3}$

Herbert de Abreu CAVALCANTI ${ }^{4}$

${ }^{1}$ Residente em Cirurgia e Traumatologia Bucomaxilofacial pela Associação Beneficente do Hospital Santa Casa de Campo Grande, 79002-251 Campo Grande - MS. Brasil

${ }^{2}$ Preceptor do Programa de Residência em Cirurgia e Traumatologia Bucomaxilofacial pela Associação Beneficente do Hospital Santa Casa de Campo Grande, 79002-251 Campo Grande - MS. Brasil

${ }^{3}$ Chefe do serviço e preceptor do programa de residência Cirurgia e Traumatologia Bucomaxilofacial pela Associação Beneficente do Hospital Santa Casa de Campo Grande, 79002-251 Campo Grande - MS. Brasil

${ }^{4}$ Coordenador do Programa de Residência em Cirurgia e Traumatologia Bucomaxilofacial pela Associação Beneficente do Hospital Santa Casa de Campo Grande, 79002-251 Campo Grande - MS. Brasil

\section{Resumo}

Introdução: Os enxertos ósseos para estes defeitos maxilofaciais já são utilizados a muitos anos, diversos técnicas ou materiais tem sidos proposto como enxertos autógenos vascularizados ou não, aloenxertos, xenogenos, aloplasticos e fatores de crescimento. A técnica de enxerto óssea consiste no transplante de um substituto ósseo para tratamento do defeito. Os enxertos ósseos autógenos ou autologos são adquiridos do próprio individuo, conta com algumas características como fornecer células vivas imunocompatíveis com o recepetor Objetivo: Apresentar o tratamento de um defeito mandibular através do uso de enxerto autógeno associado a membras de plasma rico em fibrina. Relato de caso: Uma paciente com defeito mandibular devido quadro de osteomielite após trauma, foi submetida tratamento cirúrgico com reconstrução óssea através de enxerto ósseo autógeno da crista ilíaca. Conclusão: O enxerto ósseo de crista ilíaca, apesar de necessidade de leito doador, apresenta vantagem de ter disponível grande quantidade de tecido ósseo, até atual momento não foi documentado nenhuma complicação pós-cirúrgica.

Descritores: Transplante Ósseo; Transplante Autólogo; Mandíbula.

\section{Abstract}

Introduction: Bone grafts for these maxillofacial defects have been used for many years, several techniques or materials have been proposed as autografts, vascularized or not, allografts, xenogens, alloplasts and growth factors. The bone graft technique consists of transplanting a bone substitute to treat the defect. Autologous or autologous bone grafts are purchased from the individual himself, with some characteristics such as providing live cells immunocompatible with the recipiente. Objective: To present the treatment of a mandibular defect through the use of autogenous grafts associated with fibrin-rich plasma members. Case report: A patient with a mandibular defect due to osteomyelitis after trauma, underwent surgical treatment with bone reconstruction using an autogenous bone graft from the iliac crest. Conclusion: The iliac crest bone graft, despite the need for a donor bed, has the advantage of having a large amount of bone tissue available, so far no post-surgical complication has been documented.

Descriptors: Bone Transplantation; Transplantation, Autologous; Mandible.

\section{Resumen}

Introducción: los injertos óseos para estos defectos maxilofaciales se han utilizado durante muchos años, se han propuesto varias técnicas o materiales como autoinjertos, vascularizados o no, aloinjertos, xenógenos, aloplastos y factores de crecimiento. La técnica de injerto óseo consiste en trasplantar un sustituto óseo para tratar el defecto. Los injertos óseos autólogos o autólogos se adquieren del individuo mismo, con algunas características como proporcionar células vivas inmunocompatibles con el receptor Objetivo: Presentar el tratamiento de un defecto mandibular mediante el uso de injertos autógenos asociados con miembros de plasma ricos en fibrina. Caso clínico: un paciente con un defecto mandibular debido a osteomielitis después de un trauma, se sometió a un tratamiento quirúrgico con reconstrucción ósea utilizando un injerto óseo autógeno de la cresta ilíaca. Conclusión: el injerto óseo de la cresta ilíaca, a pesar de la necesidad de un lecho de donante, tiene la ventaja de tener una gran cantidad de tejido óseo disponible, hasta el momento no se ha documentado ninguna complicación posquirúrgica.

Descriptores: Transplante Óseo; Trasplante Autólogo; Mandíbula.

INTRODUÇÃO

$$
\text { Os defeitos da mandíbula possuem }
$$
várias etiologias, desde remoção de tumores, traumas, deformidades congênitas e infecções. Várias modalidades de tratamento são propostas para estes defeitos, levando em consideração a região e o tamanho da reconstrução necessária ${ }^{1,2}$. Os enxertos ósseos para estes defeitos maxilofaciais já são utilizados a muitos anos, diversos técnicas ou materiais tem sidos proposto como enxertos autógenos vascularizados ou não, aloenxertos, xenogenos, aloplasticos e fatores de crescimento $^{1,2}$.

A técnica de enxerto óssea consiste no transplante de um substituto ósseo para tratamento do defeito ${ }^{2}$. Os enxertos ósseos autógenos ou autologos são adquiridos do próprio individuo, conta com algumas características como fornecer células vivas imunocompatíveis com o recepetor, primordiais para primeira fase de osteogênese, como osteoblastos e células osteoprogenitoras ${ }^{2}$.

Entretanto para os enxertos ósseos autógenos existe uma desvantagem aonde necessidade de um leito doador para a reconstrução óssea, diversas sítios doadores estão disponíveis como crista ilíaca, costelas, calota craniana, fíbula e até da região maxilofacial $^{1,2}$.

$$
\text { O enxerto ósseo é o padrão ouro, }
$$


entretanto as morbidades relacionadas ao leito doador, limitam sua aplicação, alternativas terapêuticas com biomateriais e fatores de crescimento para substituição óssea são usados. Os materiais aloplasticos e xenogenos apresentam como vantagem disponibilidade de grandes quantidades, sem necessitar de leito doador, entretanto é indicado para pequenos defeitos ${ }^{1,2}$. A BMP-2 é baseada em fatores de crescimento, uma proteína osteoindutora, com característica no recrutamento de células progenitoras de osteoblastos e diferenciação, células-tronco mesenquimais ${ }^{3,4}$. Atualmente a rhBMP-2 conta com liberação pela FDA (Food and Drug Administration) apenas utilização em cirurgias para levantamento do seio maxilar, apesar de relatos na literatura na utilização "off label" em casos clínicos como defeitos por resseções de tumores, traumas e fissuras ${ }^{3,4}$.

A regeneração tecidual com plasma rico em fibrina (PRF) tem sido utilizada associada aos enxertos ósseos ou de modo isolado. É uma matriz de fibrina, obtiva através centrifugação do tecido sanguíneo do próprio paciente, rico em leucócitos, plaquetas, fatores coagulações, atuando na proliferação e diferenciação de várias células e fibroblastos ${ }^{5}$.

Os aparatos tecnológicos têm ganhados espaços para planejamento das cirurgias reconstrutivas, o fluxo digital vem fornecendo recursos para diminuir tempo cirúrgico, abordagens menos invasivas e maior precisão cirúrgica. Os exames de imaginologicos como tomografias computadorizadas, prototipagem de modelos através do uso de impressoras de $3 D^{6}$.

Este trabalho tem por objetivo descrever uma reconstrução mandibular através do uso de enxerto ósseo autógeno de crista ilíaca.

\section{CASO CLÍNICO}

Paciente leucoderma, 32 anos, apresentando quadro compatível com osteomielite pós-cirúrgica em trauma mandibular envolvendo região ângulo e corpo direito devido acidente de trânsito, o exame tomográfico evidenciava-se um defeito de aproximadamente $6 \mathrm{~cm}$ (Figura 1). Foi submetida tratamento do defeito com reconstrução mandibular com enxerto ósseo autógeno de crista ilíaca.

O procedimento aconteceu sob anestesia geral, com entubação nasotraqueal. Uma incisão submandibular foi realizada para acesso ao defeito ósseo. A preparação do leito receptor foi feita com brocas esféricas por meio de descorticalização e curetagem de osso infectado, até o momento em que foi observada vitalidade do remanescente (Figura 2). Após preparo foi realizado ajuste no enxerto para adaptação das estruturas e fixação na placa de reconstrução sistema 2.4 que já havia sido instalada previamente a cirurgia para correção do defeito. Com a fixação do enxerto no leito foi adicionado osso particulado adquirido da crista ilíaca e recoberto todo enxerto com membranas de PRF (Figuras 3 e 4). A sutura foi feita por planos com fio reabsorvível de ácido poliglactina 4.0 e pele com nylon 5.0

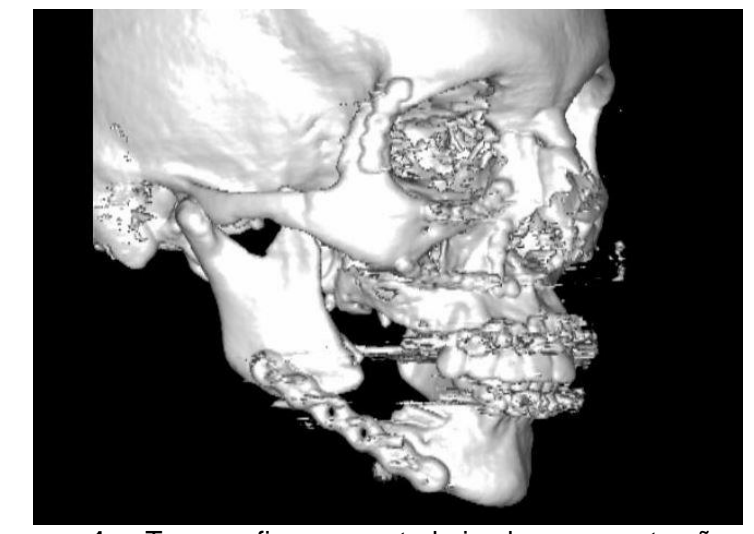

Figura 1: Tomografia computadorizada, reconstrução 3D, evidenciando defeito.

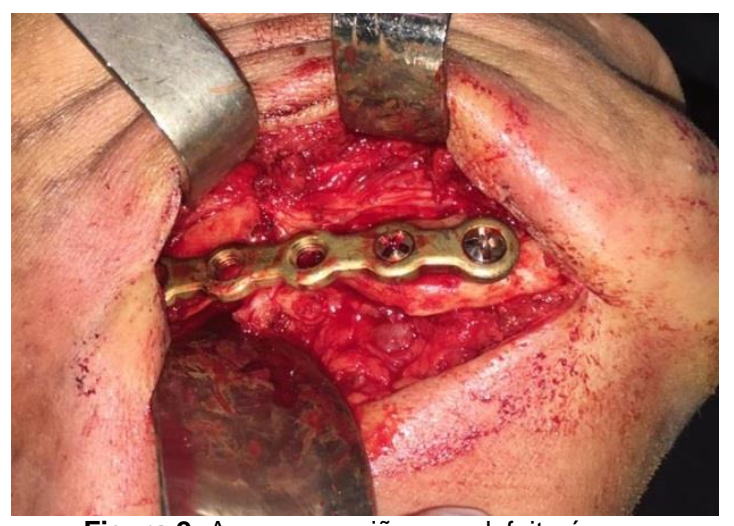

Figura 2: Acesso a região com defeito ósseo.

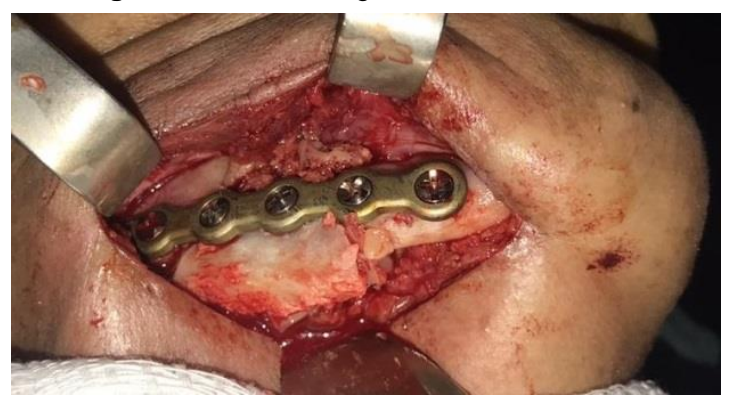

Figura 3: Adaptação do bloco ósseo de crista ilíaca e dos particulados.

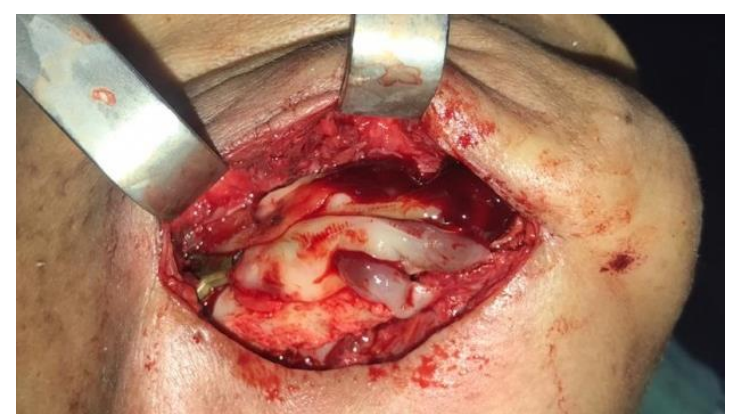

Figura 4: Aplicação das membras de PRF sobre todo tecido ósseo enxertado. 


\section{DISCUSSÃO}

As reconstruções de mandíbula com osso autógeno são geralmente utilizadas ${ }^{7}$ e vários fatores estão associados ao sucesso do tratamento como a mecânica, uma fixação rígida e tecidual do leito receptor. Em 2016, Moura et al. $^{8}$ avaliaram 926 reconstruções de mandíbula não vascularizado, em $76,1 \%$ foram obtidos através da crista ilíaca, seguido com $16,2 \%$ costelas e fíbula $5,6 \%$. As etiologias dos defeitos também foram estudadas devido a tumores benignos $(56,8 \%)$, seguida de malignos $(26,3 \%)$, lesões por arma de fogo $(7,8 \%)$ e outras causas como infecções e osteorradionecrose. Em relação as complicações no tratamento apenas dois estudos não mencionaram. Em 873 pacientes avaliados as complicações, 290 pacientes apresentaram alguma complicação, e alguns pacientes tiveram mais de uma complicação. As complicações encontradas foram $45,9 \%$ de infecções, perda do enxerto (25,9\%), deiscência $(10,3 \%)$, remoção da fixação $(4,5 \%)$, falha da fixação $(2,8 \%)$, margem recidivada $(2,4 \%)$ e outras com (8,3\%).

As indicações para o enxerto ósseo não vascularizado é recomendada em pequenos defeitos não maiores que $6 \mathrm{~mm}$, devido maior taxa de reabsorção em enxertos maiores. Em relação à osseointegração e as complicações a etiologia do defeito demonstra significância no sucesso final. Os pacientes submetidos à radioterapia para tratamento de doenças malignas apresentam pequena taxa de sucesso, sendo o enxerto vascularizado uma alternativa viável para estes casos ${ }^{8}$.

As áreas doadoras para as remoções são variadas, entretanto a crista ilíaca apresenta boa disponibilidade óssea, qualidade satisfatória, com presença de osso cortical com uma anatomia curvada parecida com a mandíbula5. Entretanto os enxertos de costela são mais indicados para os defeitos na região da cabeça da mandíbula devido a cartilagem impedir a anquilose da articulação ${ }^{8}$.

Rana et al. ${ }^{9}$, em 2011, avaliaram 178 pacientes submetidos a reconstrução e mandíbula e concluíram que os enxertos de costela apresentaram maior taxa de reabsorção quando comparado com os demais e o enxerto de osso da crista ilíaca e fíbula livre apresentaram bons resultados estéticos e funcionais previsíveis.

Queiroz et al. ${ }^{10}$ em uma revisão sistema envolvendo 282 pacientes tratados com rhBMP-2 demonstrou resultados aonde se obteve neoformações ósseas nos defeitos em todos os casos, com uma baixa quantidade de osso lamelar e com a presença de osteoblastos e osteoclastos mesmo que pequenas quantidades. A formação óssea foi em média $8,01 \mathrm{~mm}$ vertical e $4 \mathrm{~mm}$ horizontal. As complicações do uso da rhBMP-2 foram apenas locais e temporárias. $O$ atual caso relatado a paciente foi tratada com enxerto ósseo autógeno de origem de crista ilíaca devido a região do defeito, tamanho e disponibilidade de recursos do serviço.

Miron et al. $^{5}$ em revisão sistemática concluíram que a utilização das membras de plasma rico em fibrina, melhora capacidade de regeneração tecidual, seja nos defeitos ósseos ou de tecidos moles, além de diminuir taxas de infecções, com uma vantagem de apresentar-se com baixo custo e ser de origem autóloga. A reconstrução óssea relatada foi associada ao uso de PRF com intuito de se obter melhor cicatrização da região e diminuir as complicações pós cirúrgica.

O planejamento tridimensional através da confecção de modelos estereolitográficos baseados na tomografia computadorizada dos defeitos ósseos. As vantagens de ser criar, modelar e confeccionar guias fidedignos dos defeitos, o cirurgião conta com uma interação com o modelo e analisar a região a ser tratada, além diminuir tempo cirúrgico, planejar a remoção do bloco ósseo compatível com o defeito ${ }^{8,11}$.

CONCLUSÃO

As reconstruções ósseas dos defeitos mandibulares mesmo que bem consolidados na literatura, ainda são um desafio para o cirurgião. A disponibilidade de regenerações óssea com materiais modernos e auxilio de exames e aparelhos tecnológicos ampliaram e melhoraram estes tratamentos. O enxerto ósseo de crista ilíaca, apesar de necessidade de leito doador, apresenta vantagem de ter disponível grande quantidade de tecido ósseo.

Até atual momento não foi documentado nenhuma complicação pós cirúrgica, entretanto a paciente permanece em acompanhamento clinico e radiográfico, aguardando período de osteointegração para reabilitação com implantes.

\section{REFERÊNCIAS}

1. James R. Hupp, Ellis E III, Tucker MR. Cirurgia oral e maxilofacial contemporânea. Elsevier; Rio de janeiro; 2009.

2. Mazzoneto $R$, Duque Netto $H$, Nascimento FF. Enxertos ósseos em implantodontia. Napoleão. São Paulo; 2012.

3. Moreira R. Tratado de cirurgia bucomaxilofacial. Napoleão: São Paulo; 2017. 
4. Carlisle P, Guda T, Silliman DT, Burdette AJ, Talley $A D$, Alvarez $R$ et al. Localized low-dose rhBMP-2 is effective at promoting bone regeneration in mandibular segmental defects. J Biomed Mater Res B Appl Biomater. 2019; 107(5):1491-503.

5. Miron RJ, Zucchelli G, Pikos MA, Salama M, Lee $S$, Guillemette V et al. Use of platelet-rich fibrin in regenerative dentistry: a systematic review. Clin Oral Investig. 2017;21(6):1913-27.

6. Tian $T$, Zhang $T$, Ma Q, Zhang Q, Cai X. Reconstruction of Mandible: A Fully Digital Workflow From Visualized Iliac Bone Grafting to Implant Restoration. J Oral Maxillofac Surg. 2017;75(7):1403.e1-1403.e10.

7. Gallo R, Bantim YCV, Belloti ON, Fernandes BDR, Ferreira Gomes PH, Mandarino SCA et al. Reconstrução do segmento ósseo mandibular utilizando enxerto autógeno proveniente da crista ilíaca. Arch Health Invest 2018;7 (Spec Iss 3):370.

8. Moura LB, Carvalho PHA, Xavier CB, Post LK, Torriani MA, Santagata $M$ et al. Autogenous non-vascularized bone graft in segmental mandibular reconstruction: a systematic review. Int J Oral Maxillofac Surg. 2016;45(11): 1388-94.

9. Rana $M$, Warraich $R$, Kokemüller $H$, Lemound J, Essig H, Tavassol F, Eckardt A, Gellrich NC. Reconstruction of mandibular defects - clinical retrospective research over a 10-year period. Head Neck Oncol. 2011;3:23.

10. de Queiroz Fernandes J, de Lima VN, Bonardi JP, Filho OM, Queiroz SBF. Bone regeneration with recombinant human bone morphogenetic protein 2: a systematic review. J Maxillofac Oral Surg. 2018;17(1):13-8.

11. Hayden RE, Mullin DP, Patel AK. Reconstruction of the segmental mandibular defect: current state of the art. Curr Opin Otolaryngol Head Neck Surg. 2012;20(4): 231-36.

\section{CONFLITO DE INTERESSES}

Os autores declaram não haver conflitos de interesse

\section{AUTOR PARA CORRESPONDÊNCIA}

\author{
Maylson Alves Nogueira Barros \\ Rua Rui Barbosa, no 4744, apartamento 71 - Centro \\ 79002-367 Campo Grande - MS, Brasil \\ telefone: 67 99677-5267 \\ E-mail: maylson.bucomaxilofacial@gmail.com
}

